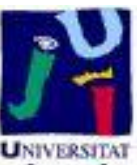

Título artículo / Títol article: Determination of the ISO face load factor in spur gear drives by the finite element modeling of gears and shafts

Autores / Autors

Roda Casanova, Victor ; Sánchez Marín, Francisco T. ; González Pérez, Ignacio ; Iserte Vila, José Luis ; Fuentes, Alfonso

Revista:

Mechanism and Machine Theory

Versión / Versió:

Pre-print

Cita bibliográfica / Cita

RODA-CASANOVA, Victor, et al. Determination bibliogràfica (ISO 690): of the ISO face load factor in spur gear drives by the finite element modeling of gears and shafts. Mechanism and Machine Theory, 2013, vol. 65, p. 1-13.

url Repositori UJI: 


\title{
Determination of the ISO face load factor in spur gear drives by the finite element modeling of gears and shafts
}

\author{
Victor Roda-Casanova ${ }^{\mathrm{a}}$, Francisco T. Sanchez-Marin ${ }^{\mathrm{a}}$, Ignacio Gonzalez-Perez ${ }^{*}$, Jose L. Iserte $^{\mathrm{a}}$, \\ Alfonso Fuentes ${ }^{\mathrm{b}}$ \\ ${ }^{a}$ Department of Mechanical Engineering and Construction, Universitat Jaume I, Castellon, Spain \\ ${ }^{b}$ Department of Mechanical Engineering, Polytechnic University of Cartagena (UPCT), Spain
}

\begin{abstract}
The face load factor is a common coefficient used in gear design standards that takes into account the uneven distribution of load across the face width of the gears caused by the mesh misalignment. In this paper, a finite element model that includes the gears and the corresponding shafts is proposed. The results obtained from the application of finite element analysis to this model are compared with those obtained from application of the ISO Standard 6336 coefficient-based method (Method $\mathrm{C}$ ). The influence of the length of gear shafts, the face width of the gears, the relative position of the gears over their shafts, the ratio between the pitch radii of the gears and the radii of their shafts, and the relation between the mesh misalignment and the face load factor, have been investigated.
\end{abstract}

Key words: Face load factor, spur gear, finite element analysis, ISO Standard 6336

\section{Introduction}

Spur gear drives are the most common way to transmit power between parallel shafts. In order to predict the load capacity of spur gear drives, several methods can be found in the literature. Among these methods, the most common applied ones use influence factors. Many handbooks and standards provide design guides for gears through application of such influence factors, being well known the ISO Standard 6336 [1, 2, 3] and the AGMA Standard 2001-D04 [4].

The influence factors defined in gear standards have been the subject of extensive analysis regarding their calculation or their repercussion on the load capacity $[5,6,7]$. One of these factors is the face load factor, that is named as $K_{H \beta}$ by the ISO Standard. The face load factor is defined as the ratio between the peak load intensity and the mean load intensity across the face width of the gears. This factor takes into account the effects of non-uniform load distribution over the face width caused by the mesh misalignment in the plane of action. This misalignment can be caused by elastic deformations of gears, shafts, and bearings as well as for manufacture and assembly deviations, bearing clearances or dynamic effects.

Due to its complexity, some authors have written guides to calculate the face load factor $[8,9]$. Atanasovska [10] proposed a finite element model to calculate the face load factor, and studied several causes that produce variations in the load capacity of a gear, like mesh stiffness [11], the

\footnotetext{
${ }^{*}$ Corresponding author

Email address: ignacio.gonzalez@upct.es (Ignacio Gonzalez-Perez)

${ }^{1}$ Tel: +968326429; Fax: +968326449
} 
addendum coefficient [12], or the nominal transmitted load [13]. Others have contributed investigating how the load is distributed over the gear face width [14, 15], and have studied numerically, analytically, or empirically, the elastic deformations of the gear teeth $[16,17]$ and the effect of manufacturing and assembly deviations $[18,19]$. There are fewer authors that have studied the elastic deformations of the shafts that support the gears [20,21], and how their mechanical behavior affects to the gear load capacity.

Many of the authors mentioned above use bi-dimensional finite element models $[11,13,16]$ whereas few of them use more advanced three-dimensional finite element models [10, 18, 19]. Generally, these works are focused in the modeling of the gears and the gear tooth surfaces, but they seldom include shafts or shaft supports.

The main goals of this work are the following:

(1) Proposal of a finite element model that includes the modeling of gears and shafts for the determination of the face load factor by application of finite element analysis.

(2) Comparison of the face load factor obtained through the finite element analysis by using the proposed finite element model with that obtained by application of the ISO Standard coefficient-based method (Method C).

(3) Investigation of the influence of the relative position of gears along their shafts, the face width of the gears, the ratio between the pitch radii of gears and the radii of their respective shafts, and the length of the shafts.

\section{Description of the finite element model}

The proposed physical model is obtained from a conventional spur gear drive composed of one pinion, one wheel, and two supporting shafts (Figure 1). The shafts are perfectly aligned and are supported at their ends by bearings where bending is allowed. The gears are rigidly connected to their respective shafts and the active parts of the tooth surfaces are based on involute profiles. A torque $T$ is applied to one of the ends of the pinion shaft whereas the motion on the wheel shaft is restricted by blocking the rotation on one of their ends.

The generation of the finite element model starts from the physical model shown in Figure 1 and is accomplished as follows:

(1) The gear teeth are meshed using the method described in [22]. Figure 2 shows the finite element mesh of one gear tooth. A rigid surface is considered around the rim of the gear tooth. Such a rigid surface will be rigidly connected to a reference node on the gear shaft. The motions defined on each reference node are transmitted directly to the corresponding rigid surface since the reference node and the rigid surface constitutes a rigid body [22].

(2) Reference nodes $M_{1}$ and $M_{2}$ are defined on the pinion and wheel shafts (Figure 3 ) for the transmission of motion from the pinion shaft to the pinion tooth and from the wheel tooth to the wheel shaft through the respective rigid surfaces. A model based on one pair of gear teeth has been considered in order to achieve the highest refinement of the finite element mesh.

(3) Beam elements with the same circular section are considered along the pinion and the wheel shafts. As shown in [23], the three-dimensional finite element model of the shafts using eightnode hexahedral "brick" elements can be replaced by a one dimensional finite element model of the shafts using beam elements, yielding the same results. 


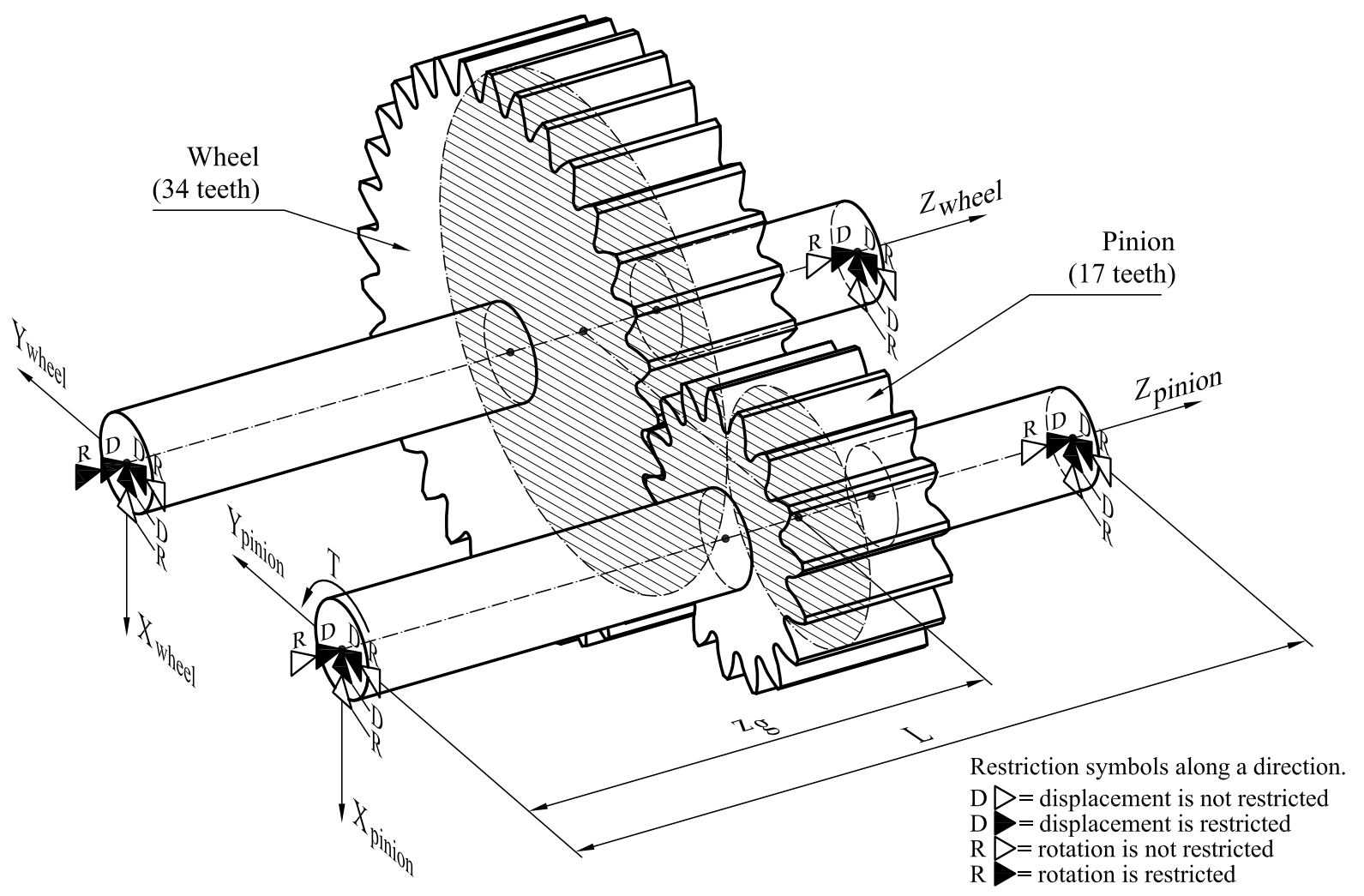

Figure 1: Physical model of a spur gear drive.

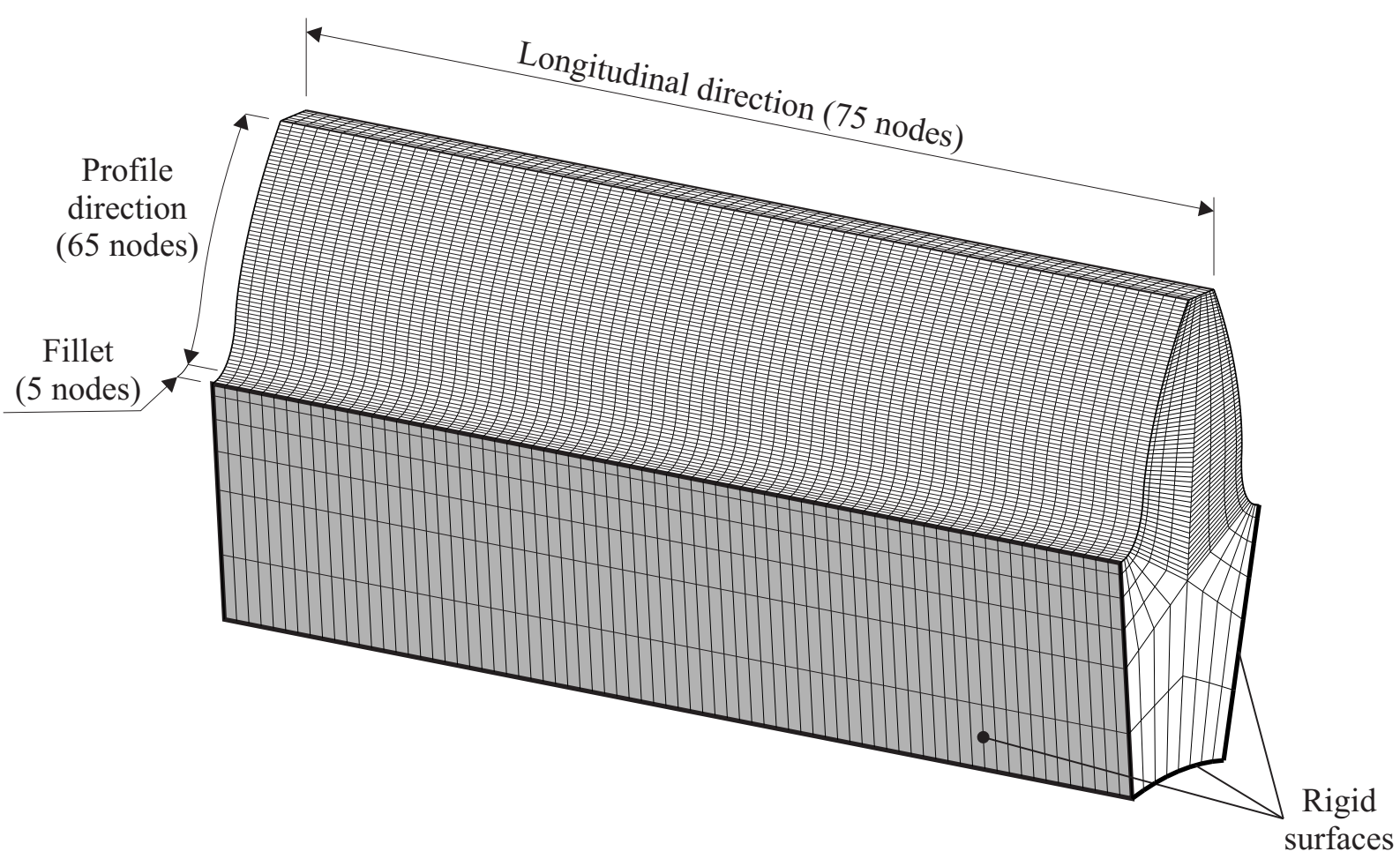

Figure 2: Finite element mesh for one gear tooth. 


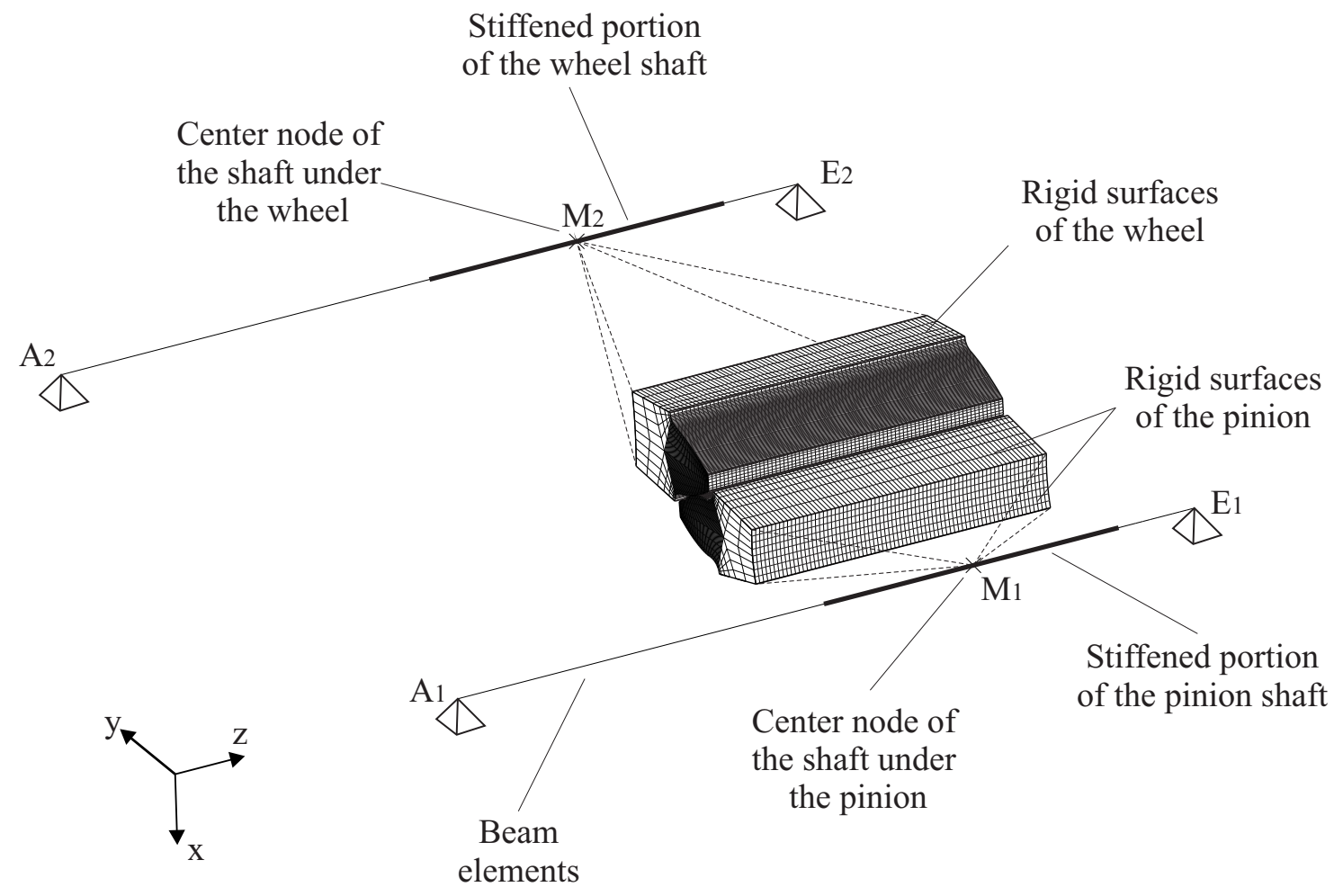

Figure 3: Finite element model of the gear drive.

(4) At the stiffened portions of the pinion and wheel shafts, the radii of the circular sections of the beam elements are increased up to the pitch radii of the gears.

(5) A torque $T$ is applied at node $A_{1}$ whereas rotation is blocked at node $A_{2}$.

\section{Determination of the face load factor by finite element analysis}

The determination of the face load factor by finite element analysis, $K_{H \beta-F E M}$, is accomplished as follows:

(1) At each node inside the contact area, the computed pressure $p_{i}$ multiplied by the height of the element $h_{i}$ provides the nodal load intensity $(F / b)_{i}$ as

$$
(F / b)_{i}=p_{i} \cdot h_{i}
$$

(2) The loads intensities $(F / b)_{i}$ for all the nodes with the same coordinate $z$ are added up to obtain the load intensity $(F / b)$ as a function of $z$

$$
(F / b)(z)=\sum(F / b)_{i}
$$

where subindex $i$ corresponds to those nodes with the same coordinate $z$.

(3) A piecewise linear function of the load intensity $(F / b)(z)$ is obtained along the face width as it is shown in Figure 4. 


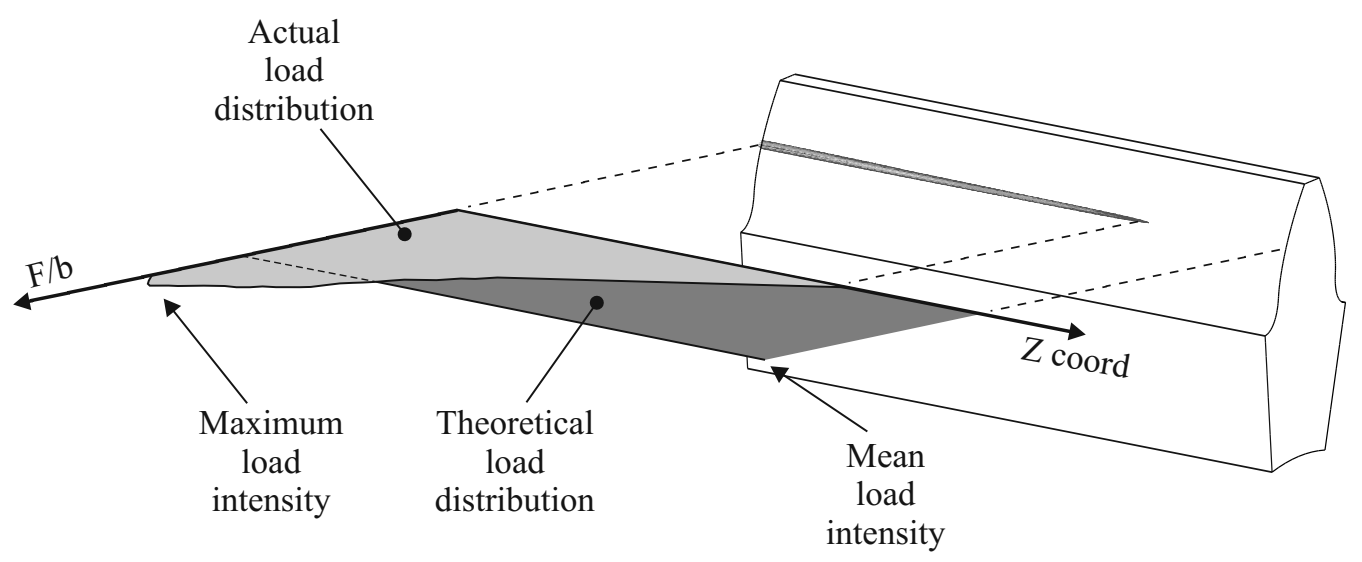

Figure 4: For the determination of the face load factor by finite element analysis.

(4) The mean load intensity $(F / b)_{m}$ is obtained as the integral of function $(F / b)(z)$ divided by the face width $b$. The integral of the function $(F / b)(z)$ is solved numerically by the quadrature formula of the closed Newton-Cotes type corresponding to the trapezoidal rule [24]. Figure 4 shows the mean load intensity.

(5) The maximum value of the function $(F / b)(z)$ is identified as the maximum load intensity $(F / b)_{\max }$.

(6) Finally, the face load factor is obtained as

$$
K_{H \beta-F E M}=\frac{(F / b)_{\max }}{(F / b)_{m}}
$$

\section{Application of the ISO Standard coefficient-based method}

Standard ISO 6336 [1] will be considered here for the determination of the face load factor in the physical model represented in Figure 1. The ISO Method C is a coefficient-based method widely applied in industry and will be used here in order to compare the obtained results from those determined by application of the finite element method. The face load factor obtained by the Method $\mathrm{C}$ is called $K_{H \beta-C}$.

The face load factor $K_{H \beta-C}$ is calculated from the mean load intensity across the face width $\left(F_{m} / b\right)$, the mesh stiffness $c_{\gamma \beta}$, and an effective total mesh misalignment $F_{\beta y}$. Depending on whether the bearing contact is spread over (i) the whole face width or (ii) partially on the tooth surface, the factor $K_{H \beta-C}$ is determined as [1]

(i)

$$
K_{H \beta-C}=1+\frac{F_{\beta y} c_{\gamma \beta}}{2\left(F_{m} / b\right)}
$$

(ii)

$$
K_{H \beta-C}=\sqrt{\frac{2 F_{\beta y} c_{\gamma \beta}}{\left(F_{m} / b\right)}}
$$


The most significant parameter in the determination of $K_{H \beta-C}$ is $F_{\beta y}$, than can be determined as $[1]$

$$
F_{\beta y}=F_{\beta x} \cdot \chi_{\beta}
$$

where $F_{\beta x}$ is the initial equivalent misalignment before running-in and $\chi_{\beta}$ is a running-in factor. $F_{\beta x}$ represents the absolute value of the sum of deformations, displacements and manufacturing deviations of pinion and wheel, measured in the plane of action.

Since $K_{H \beta-C}$ is being calculated for the physical model represented in Figure 1, where perfect involute tooth surfaces are considered, a factor $\chi_{\beta}=1$ is taken.

The factor $F_{\beta x}$ is defined as [1]

$$
F_{\beta x}=1.33 \cdot f_{s h} \cdot f_{s h 2} \cdot f_{m a} \cdot f_{c a} \cdot f_{b e}
$$

where

- $f_{s h}$ counts for the deformations of the pinion and the pinion shaft.

- $f_{s h 2}$ counts for the deformations of the wheel and the wheel shaft.

- $f_{m a}$ counts for the manufacturing deviations of pinion and wheel.

- $f_{c a}$ counts for the deformations of the gear case.

- $f_{b e}$ counts for the displacements of the bearings.

In this study, $f_{m a}=0, f_{c a}=0$, and $f_{b e}=0$, since only the influence of pinion deformations, wheel deformations, pinion shaft deformations, and wheel shaft deformations, on the face load factor, are investigated.

Factor $f_{s h}$ is defined in [1] as

$$
f_{s h}=0.023 \cdot \frac{F_{m}}{b}\left[\left|1.0+K^{\prime} \cdot \frac{l \cdot s}{d_{1}^{2}} \cdot\left(\frac{d_{1}}{d_{s h 1}}\right)^{4}-0.3\right|+0.3\right]\left(\frac{b}{d_{1}}\right)^{2}
$$

where $l$ is the length of the shaft ( $L$ in Figure 1), $s=\left|\frac{L}{2}-z_{g}\right|$ (see Figure 1), $d_{1}$ is the pitch radius of the pinion, $d_{s h 1}$ is the pinion shaft radius, and $K^{\prime}$ is a factor that takes into account the location of the gears over the shafts in relation to the torque input.

Factor $f_{s h 2}$ is defined in a similar way

$$
f_{s h 2}=0.023 \cdot \frac{F_{m}}{b}\left[\left|1.0+K^{\prime} \cdot \frac{l \cdot s}{d_{2}^{2}} \cdot\left(\frac{d_{2}}{d_{s h 2}}\right)^{4}-0.3\right|+0.3\right]\left(\frac{b}{d_{2}}\right)^{2}
$$

where $d_{2}$ is the pitch radius of the wheel, and $d_{s h 2}$ is the wheel shaft radius. In this study, $d_{s h 2}=d_{s h 1}=d_{s h}($ see Table 1$)$.

\section{Numerical examples}

Table 1 shows the design data of the spur gear drive represented in Figure 1. Four design parameters are considered as variables:

- the face width $b$ (4 values), 
Table 1: Design data of the spur gear drive represented in Figure 1.

\begin{tabular}{|l|c|c|}
\hline Parameter & Variable & Values \\
\hline \hline Module & $m$ & $4 \mathrm{~mm}$ \\
\hline Pressure angle & $\alpha$ & $25^{\circ}$ \\
\hline Number of teeth of the pinion & $z_{1}$ & 17 \\
\hline Number of teeth of the gear & $z_{2}$ & 34 \\
\hline Face width & $b$ & $20 \mathrm{~mm}, 40 \mathrm{~mm}, 60 \mathrm{~mm}, 80 \mathrm{~mm}$ \\
\hline Profile shift coefficient of pinion and gear & $x_{1}, x_{2}$ & 0 \\
\hline Addendum & $h_{a P}$ & $4 \mathrm{~mm}$ \\
\hline Dedendum & $h_{f P}$ & $5 \mathrm{~mm}$ \\
\hline Length of the shaft & $L$ & $100 \mathrm{~mm}, 150 \mathrm{~mm}, 200 \mathrm{~mm}, 300 \mathrm{~mm}$ \\
\hline Shaft diameters & $d_{s h}$ & $25 \mathrm{~mm}, 30 \mathrm{~mm}, 35 \mathrm{~mm}$ \\
\hline Position of the gears over the shafts & $z_{g}$ & $0.2 L, 0.25 L, 0.3 L, 0.4 L, 0.45 L, 0.5 L$ \\
& $E$ & $0.55 L, 0.6 L, 0.7 L, 0.75 L, 0.8 L$ \\
\hline Young's Modulus & $E$ & $210000 \mathrm{MPa}$ \\
\hline Poisson's ratio & $\nu$ & 0.3 \\
\hline Torque & $T$ & $120 \mathrm{Nm}$ \\
\hline Angular position of gears & $\theta_{1}, \theta_{2}$ & Gears contacting at the pitch line \\
\hline
\end{tabular}

- the length of the shafts $L$ (4 values),

- the shaft diameters $d_{s h}$ (3 values), and

- the location of the gears over the shafts $z_{g}$ (11 values).

Considering the combinations of values showed in Table 1 and gear mounting restrictions over the shaft, due to bearing location and gear face widths, a total of 486 cases of design have been finally investigated. The eleven values of $z_{g}$ cover the applicable range suggested by ISO Standard 6336 [1]. The gears have been considered contacting at the pitch line in all cases of design since the face load factor is determined in the Standard ISO 6336 through the nominal tangential load, which is calculated from the nominal torque in the transverse plane at the reference cylinder.

The finite element model considered in this study has 86038 elements with 96650 nodes (see the mesh on the pinion tooth shown in Figure 2). Pinion and wheel teeth are meshed with eight-node hexahedral "brick" elements elements of type C3D8I [25]. Pinion and wheel shafts are meshed with beam elements of type B31 [25]. The beam elements have a uniform length around $1 \mathrm{~mm}$ and a constant diameter $d_{s h}$. However, for those beam elements located on the stiffened portion of the pinion and the wheel shafts, the pitch diameters of the gears are considered instead. The material for gears and shafts is steel (see properties in Table 1). A torque $T=120 \mathrm{Nm}$ is applied to the pinion shaft. This torque provides a mean tangential load $F_{m}=3529.412 \mathrm{~N}$.

Figure 5 shows the bearing contact on the pinion tooth surface for different locations of the gears over the shafts. It is shown that the bearing contact, due to shaft deformations, is shifted towards the tooth edge as the gears are located closer to the bearings.

\subsection{Face load factor $K_{H \beta-F E M}$ vs. mesh misalignment}

A relation between the face load factor and the mesh misalignment is expected. Two types of errors of alignment are considered: 

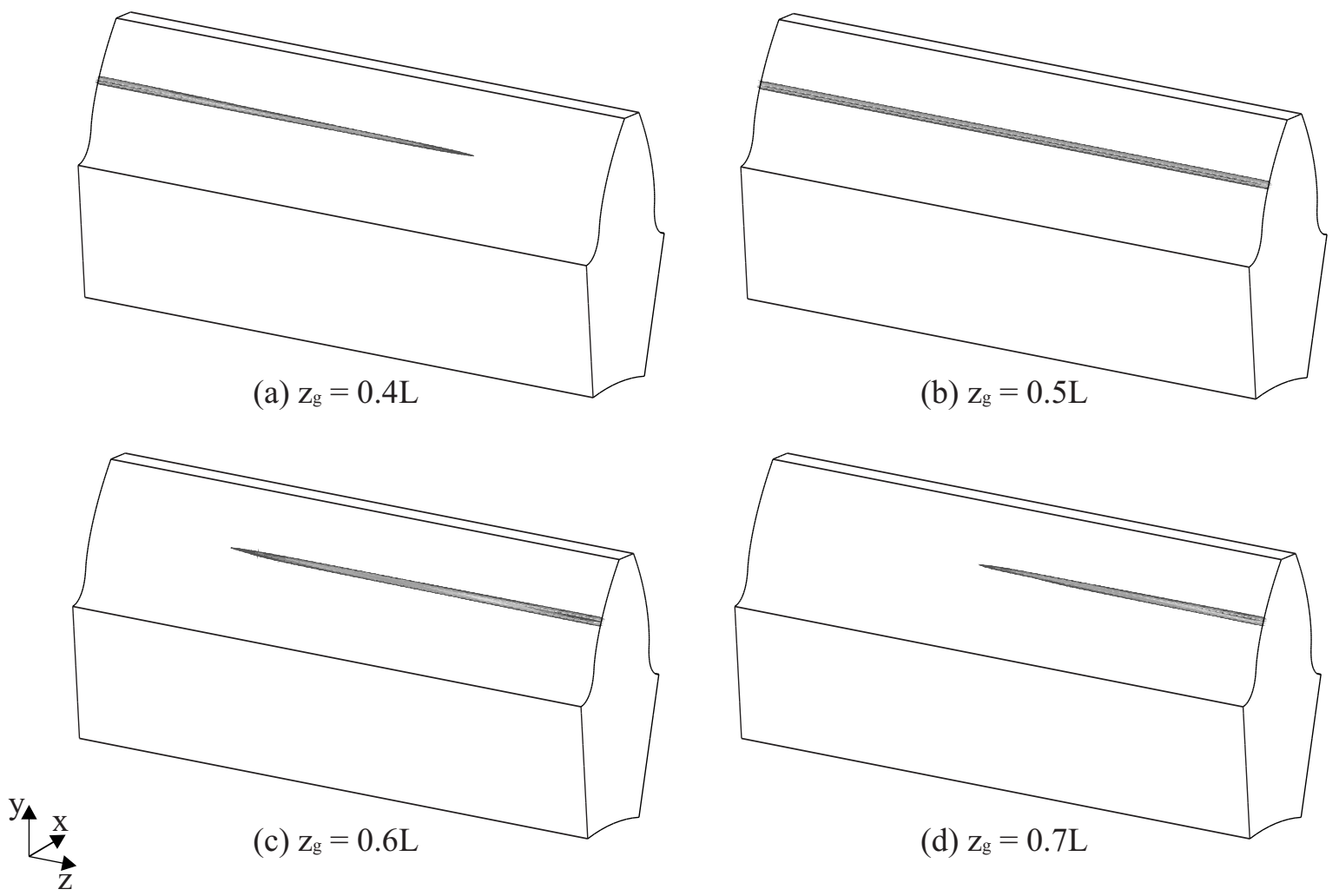

Figure 5: Bearing contact on the pinion tooth surface in the case of $b=40 \mathrm{~mm}$., $L=150 \mathrm{~mm}$., $d_{s h}=25 \mathrm{~mm}$. when: (a) $z_{g}=0.4 L$, (b) $z_{g}=0.5 L$, (c) $z_{g}=0.6 L$, and (d) $z_{g}=0.7 L$.

- The center distance error.

- The angular misalignment, that is obtained as

$$
\phi=\arctan \left[\tan \left(\phi_{Y Z}\right) \cdot \cos \left(\phi_{X Z}\right)\right]
$$

where $\phi_{Y Z}$ is the angular error in the plane $Y Z$ and $\phi_{X Z}$ is the angular error in the plane $X Z$ (see Figure 1). Such values are computed after the finite element analysis has been carried out, considering the displacements and rotations of the reference nodes.

Figures 6(a) and 6(c) show the relation between the angular misalignment in the plane of action of the gears and the face load factor $K_{H \beta-F E M}$ for some cases of design. A relation between the angular misalignment and the face load factor can be observed. In fact, when a maximum in the angular misalignment variation is reached, a maximum in the face load factor variation is obtained. These maximum values are obtained because of the existence of two opposed effects as the gears are locater closer to one of the bearings:

(1) The angular deformation of the shaft increases from the middle of the shaft to one of the ends.

(2) The angular deformation of the shaft decreases since the total force is closer to one of the ends.

Figures $6(\mathrm{~b})$ and $6(\mathrm{~d})$ show the relation between the center distance error between the gears and the face load factor $K_{H \beta-F E M}$ for the same cases of design. No relation between the center distance error and the face load factor was found. 

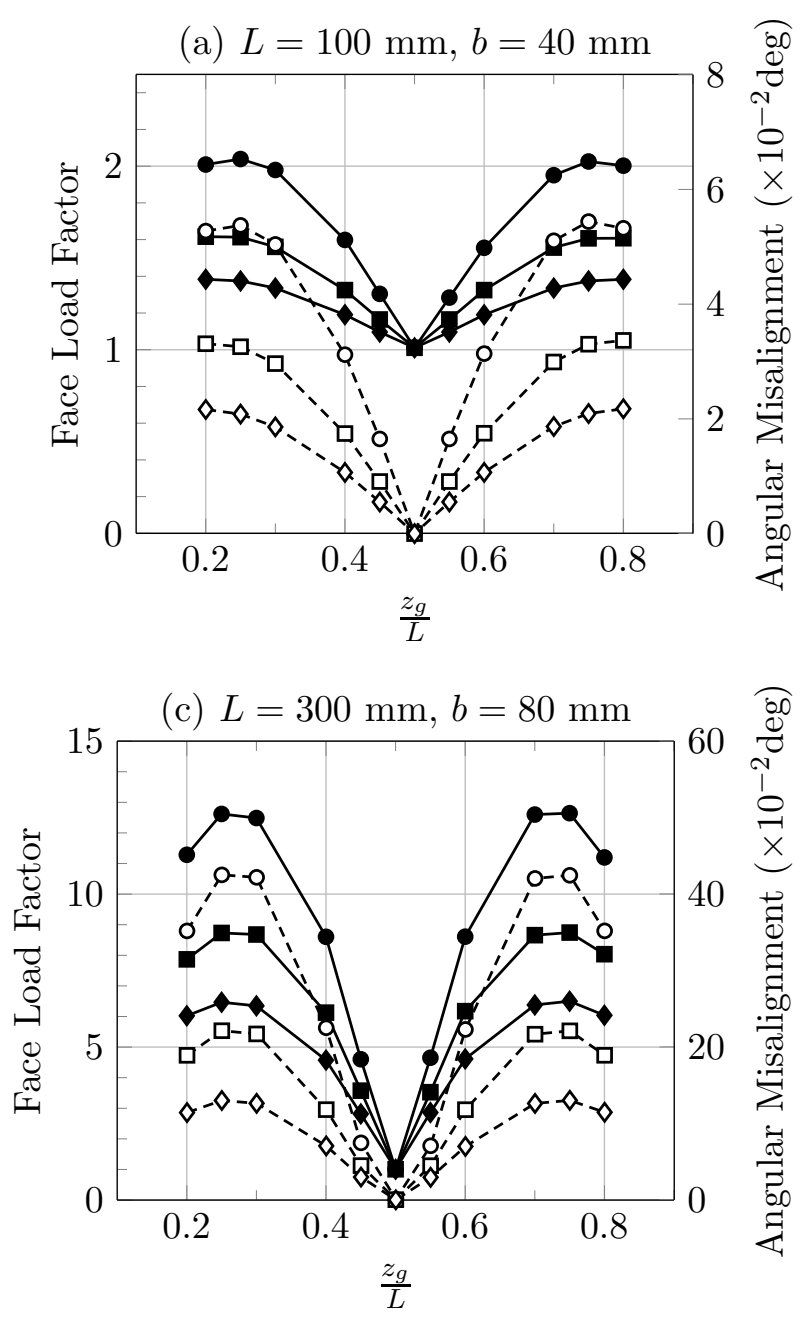

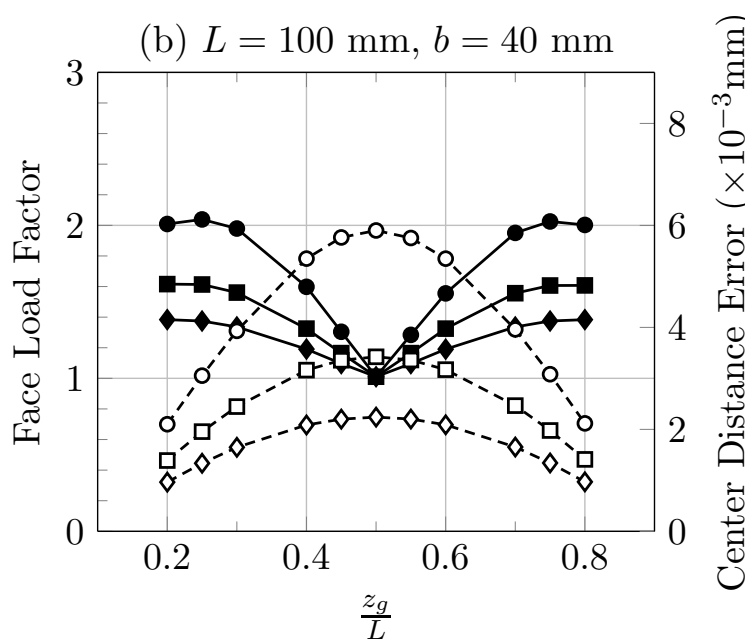

(d) $L=300 \mathrm{~mm}, b=80 \mathrm{~mm}$

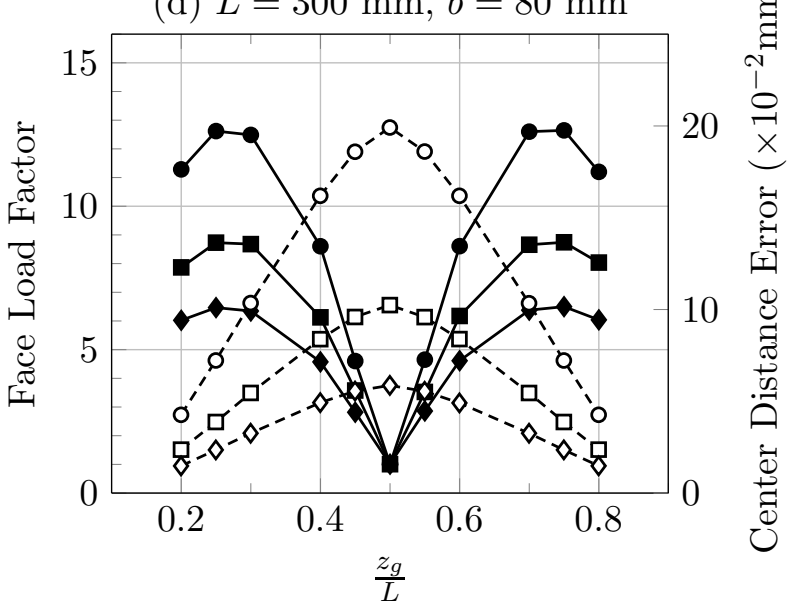

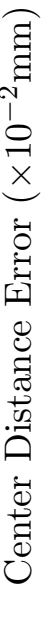

$\bullet K_{H \beta-F E M^{-}} d_{s h} 25 \rightarrow-K_{H \beta-F E M^{-}} d_{s h} 30 \longrightarrow K_{H \beta-F E M^{-}} d_{s h} 35$

-。-MIS- $d_{s h} 25 \quad$ - - - MIS- $d_{s h} 30 \quad-\diamond$ - MIS- $d_{s h} 35$

Figure 6: Comparison for some cases of design of the face load factor $K_{H \beta-F E M}$ with: (a) and (c) the angular misalignment and, (b) and (d), the center distance error.

\subsection{Face load factors $K_{H \beta-F E M}$ and $K_{H \beta-C}$ vs. shaft diameter}

Figure 7 shows the variations of the face load factors $K_{H \beta-F E M}$ and $K_{H \beta-C}$ with the shaft diameter, $d_{s h}$, for some cases of design.

Mesh stiffness $c_{\gamma \beta}$ has been calculated according to the ISO Standard coefficient-based method [1]. Its value is $15.52 \frac{\mathrm{N}}{\mathrm{mm} \cdot \mu \mathrm{m}}$ for $b=20 \mathrm{~mm}, 15.04 \frac{\mathrm{N}}{\mathrm{mm} \cdot \mu \mathrm{m}}$ for $b=40 \mathrm{~mm}, 13.60 \frac{\mathrm{N}}{\mathrm{mm} \cdot \mu \mathrm{m}}$ for $b=60 \mathrm{~mm}$, and $12.65 \frac{\mathrm{N}}{\mathrm{mm} \cdot \mu \mathrm{m}}$ for $b=80 \mathrm{~mm}$.

Parameter $K^{\prime}$ shown in Eqs. (8) and (9) is taken as $K^{\prime}=0.48$ or $K^{\prime}=-0.48$ depending on the location of the gears over the shafts respect to the input torque. Stiffening is assumed for the cases of design investigated [1].

Figures 7(a), 7(b), and 7(c) show a decrement of the face load factor as the shaft diameter increases in case of $z_{g} \neq 0.5 \mathrm{~L}$. This is due to an increment in the stiffness of the transmission that 

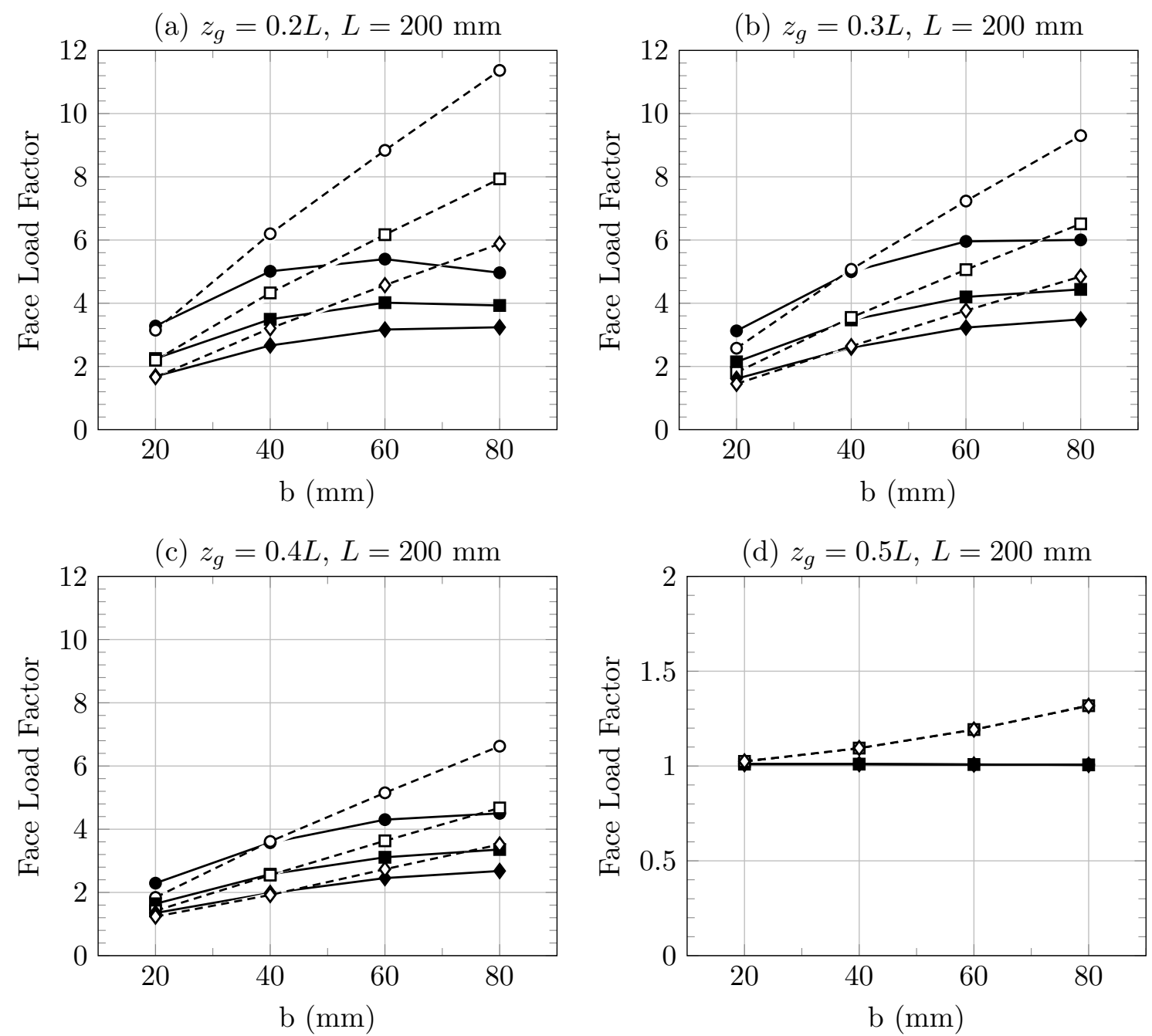

$\bullet-K_{H \beta-F E M}-d_{s h} 25 \rightarrow-K_{H \beta-F E M^{-}} d_{s h} 30 \longrightarrow-K_{H \beta-F E M^{-}} d_{s h} 35$

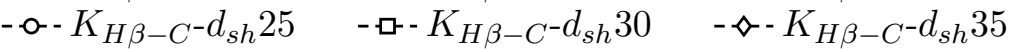

Figure 8: Variation of $K_{H \beta-F E M}$ and $K_{H \beta-C}$ with several values of $b$ for some cases of design.

For some cases of design, the values of $K_{H \beta-F E M}$ and $K_{H \beta-C}$ coincide with each other.

\subsection{Face load factors $K_{H \beta-F E M}$ and $K_{H \beta-C}$ vs. length of the shafts}

Figure 9 shows the variations of the face load factors $K_{H \beta-F E M}$ and $K_{H \beta-C}$ with the length of the shafts, $L$, for some cases of design.

A non-linear increment of $K_{H \beta-F E M}$ and an almost linear increment of $K_{H \beta-C}$ for all the cases of design shown in Figure 9 are observed. In the case of $z_{g}=0.5 L$ (not shown in Figure 9) the factors $K_{H \beta-F E M}$ and $K_{H \beta-C}$ remain constant with a lower value of $K_{H \beta-F E M}$ than the value of $K_{H \beta-C}$. 

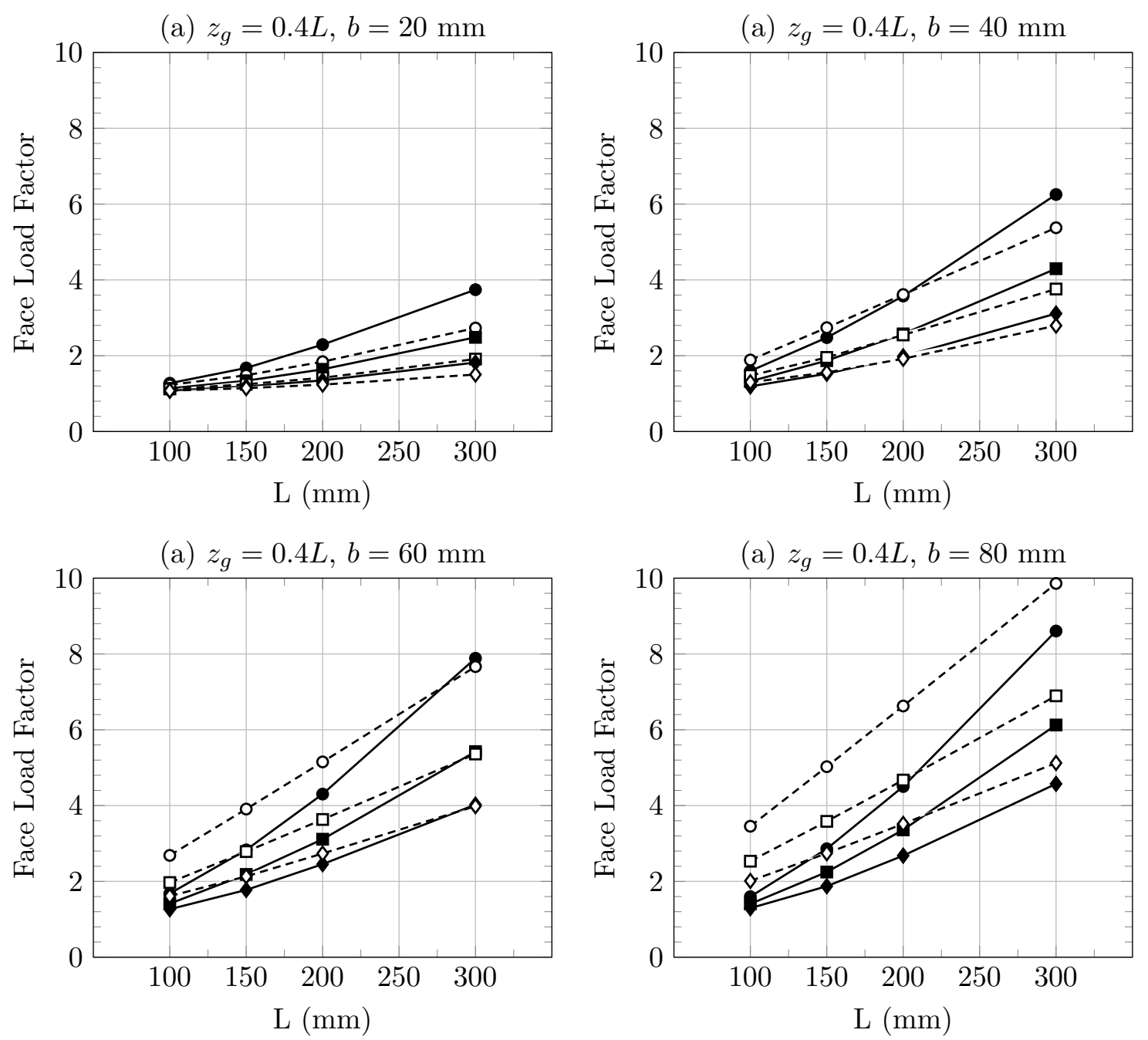

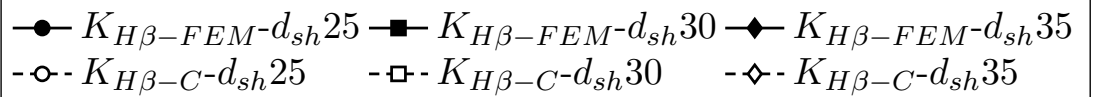

Figure 9: Variation of $K_{H \beta-F E M}$ and $K_{H \beta-C}$ with several values of $L$ for some cases of design.

5.5. Face load factors $K_{H \beta-F E M}$ and $K_{H \beta-C}$ vs. the relative position of the gears over the shafts

Figure 10 shows the variations of the face load factors $K_{H \beta-F E M}$ and $K_{H \beta-C}$ with the relative position of the gears over the shafts, $z_{g}$, for some cases of design.

Increments of the factors $K_{H \beta-F E M}$ and $K_{H \beta-C}$ are observed in Figure 10 as the gears location moves away from the middle of the bearing span. A maximum in the variation of the factor $K_{H \beta-F E M}$ is observed when the gears location is at the midway between the supports and the middle of the bearing span $\left(z_{g}=0.25 L\right.$ and $\left.z_{g}=0.75 L\right)$. Such a maximum is not reached for the factor $K_{H \beta-C}$. These results for the factor $K_{H \beta-F E M}$ are in accordance with the variation of the angular misalignment shown in Figures 6(a) and 6(d).

Figure 10 shows as well that symmetrical results respect to the gears location at the middle of the bearing span $\left(z_{g}=0.5 L\right)$ are obtained for both face load factors. 

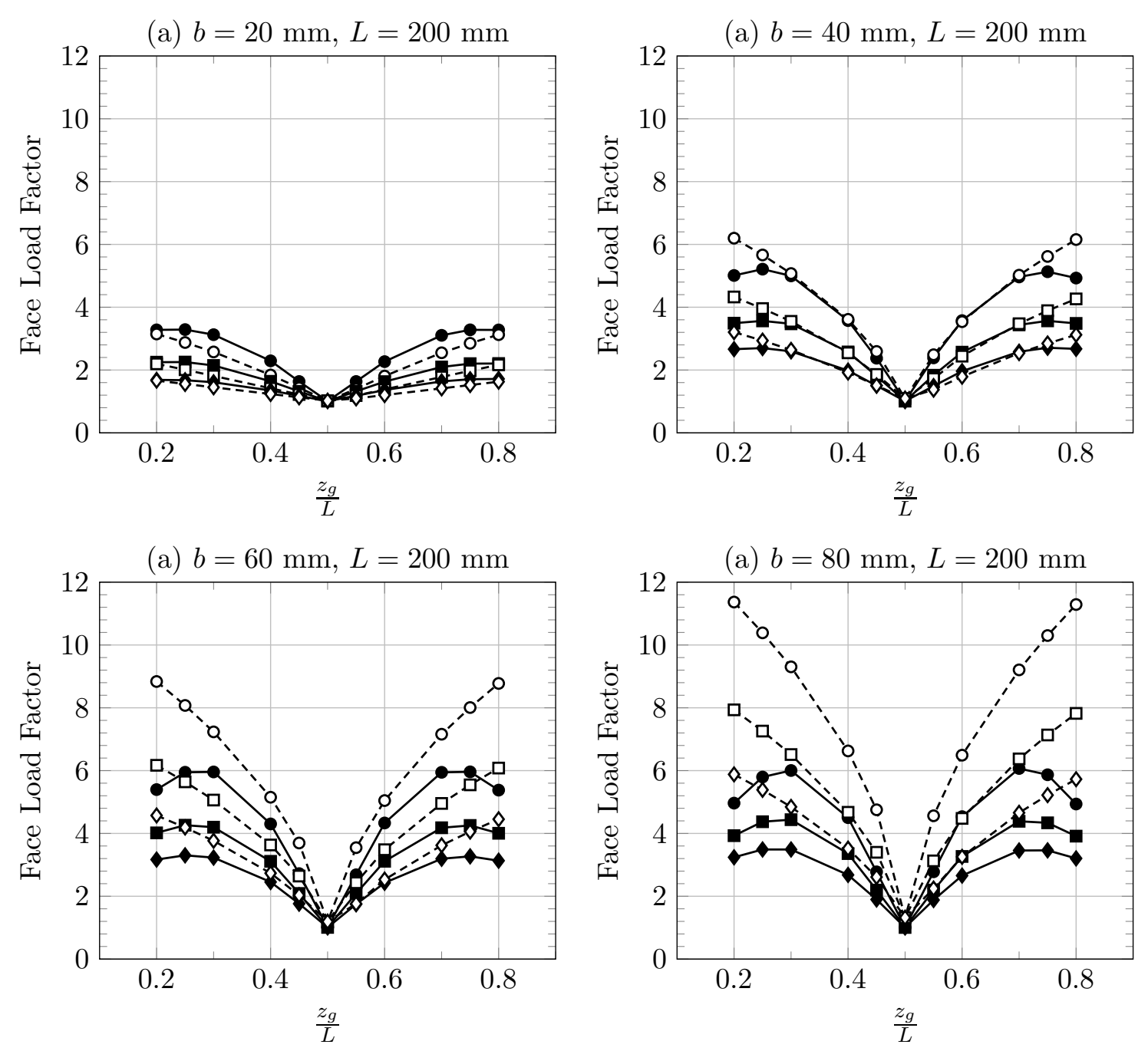

$\bullet-K_{H \beta-F E M^{-}} d_{s h} 25--K_{H \beta-F E M^{-}} d_{s h} 30 \multimap-K_{H \beta-F E M^{-}} d_{s h} 35$

-॰- $K_{H \beta-C}-d_{s h} 25 \quad$ - $-K_{H \beta-C}-d_{s h} 30 \quad-\diamond-K_{H \beta-C}-d_{s h} 35$

Figure 10: Variation of $K_{H \beta-F E M}$ and $K_{H \beta-C}$ with several values of $z_{g}$ for some cases of design.

\subsection{Relative difference between $K_{H \beta-C}$ and $K_{H \beta-F E M}$ vs. the ratio $b / L$}

The relative difference between $K_{H \beta-C}$ and $K_{H \beta-F E M}$ has been evaluated in the 486 cases of design as

$$
\epsilon_{r e l}=\frac{K_{H \beta-C}-K_{H \beta-F E M}}{K_{H \beta-F E M}} \cdot 100
$$

Figure 11 shows the obtained values of $\epsilon_{r e l}$ in the case of four representative values of the ratio $z_{g} / L$. The variation of $\epsilon_{r e l}$ with the ratio $b / L$ has been investigated for each representative value of $z_{g} / L$. A linear regression between $\epsilon_{r e l}$ and $b / L$ has been obtained and shows an increasing tendency with the ratio $b / L$ with some dispersion.

It is possible to obtain an envelope curve to the minimum values of $\epsilon_{\text {rel }}$ and an envelope curve to the maximum values of $\epsilon_{r e l}$ for each representative value of $z_{g} / L$. Figure 12(a) shows the envelope 

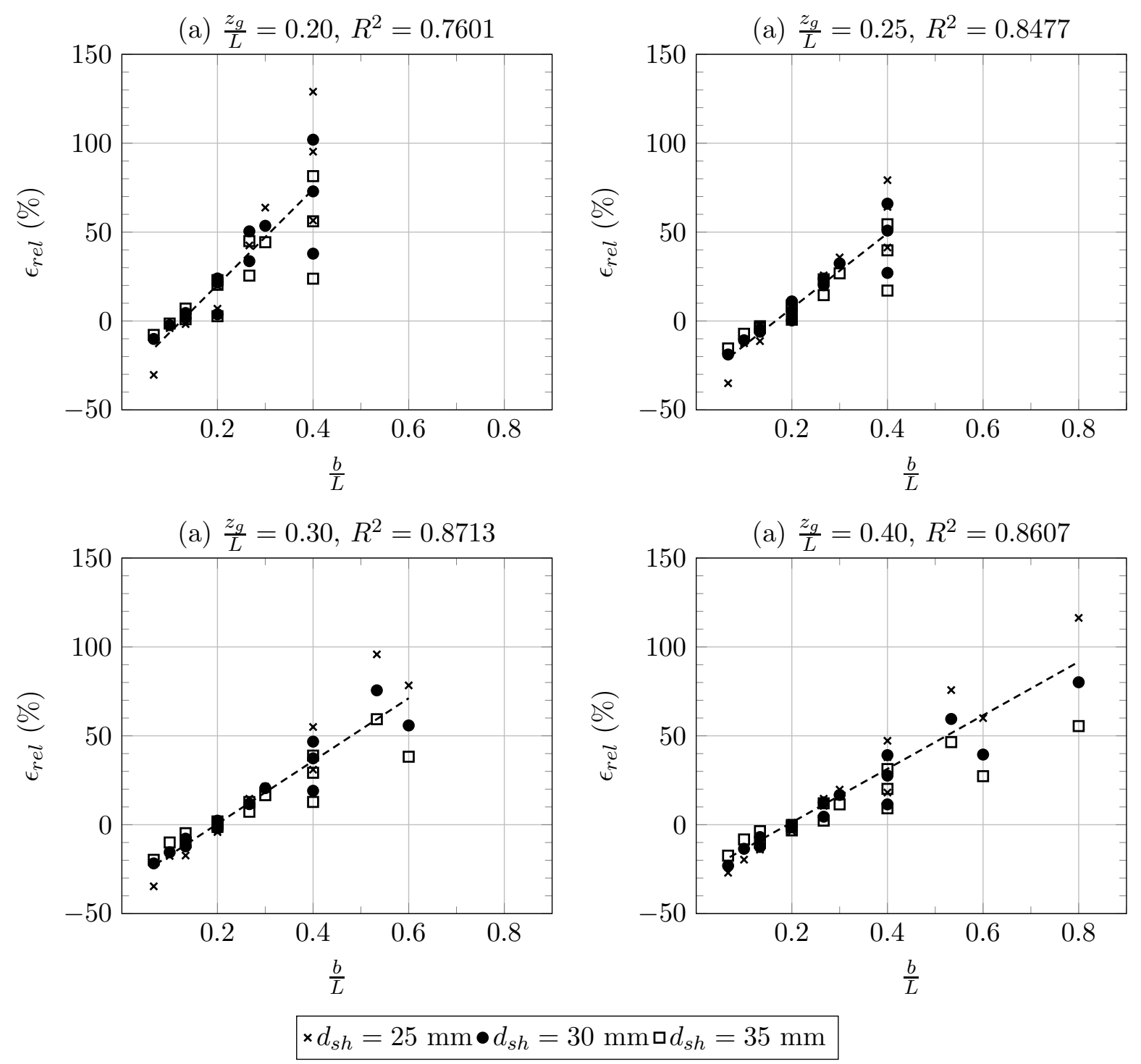

Figure 11: Linear regressions between $\epsilon_{\text {rel }}$ and the ratio $b / L$ for four representative values of $z_{g} / L$.

curve to the minimum values of $\epsilon_{r e l}$ for the case of $z_{g} / L=0.4$. Figure 12(b) shows the envelope curve to the maximum values of $\epsilon_{\text {rel }}$ for the same case.

All the information about the maximum and minimum values of $\epsilon_{r e l}$ have been summarized in the graphs of Figure 13 for all the cases of design that have been investigated. Figure 13(a) shows the minimum values of $\epsilon_{r e l}$ while Figure 13(b) shows the maximum values of $\epsilon_{r e l}$ for each pair of values $\left(z_{g} / L, b / L\right)$.

The shaded zone shown in Figure 13(a) represents the combinations of values $\left(z_{g} / L, b / L\right)$ where the minimum values of $\epsilon_{r e l}$ are negative. The shaded zone shown in Figure 13(b) represents the combinations of values $\left(z_{g} / L, b / L\right)$ where the maximum values of $\epsilon_{\text {rel }}$ are negative. Those shaded zones may be of special attention for the gear designer since the factor $K_{H \beta-C}$ is lower than the factor $K_{H \beta-F E M}$. 

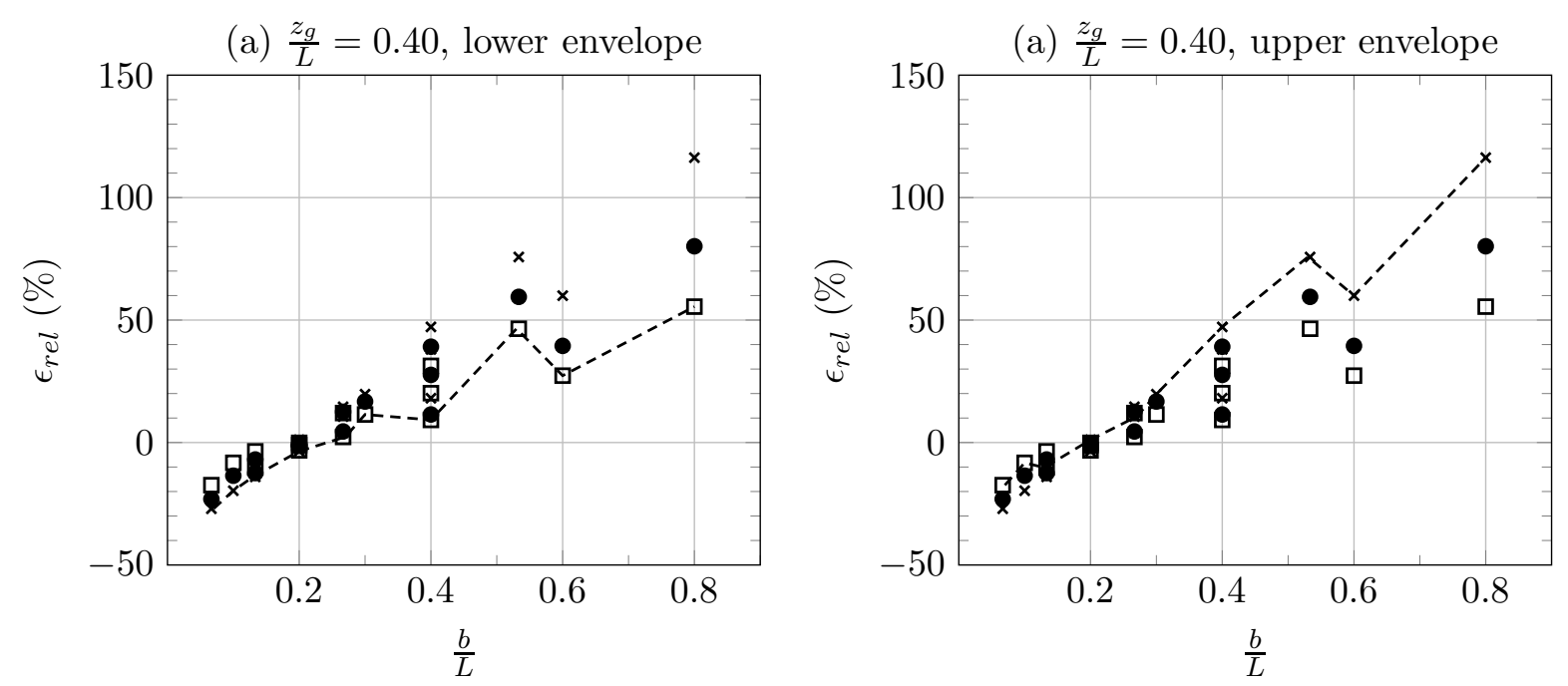

Figure 12: Envelope curves to the (a) minimum values and (b) maximum values of $\epsilon_{r e l}$ in the case of $z_{g} / L=0.4 L$.

\section{Conclusions}

The performed research work allows the following conclusions to be drawn:

(1) A finite element model that includes gears and shafts and a method for the determination of the face load factor by finite element analysis have been proposed.

(2) The results of the face load factor obtained by finite element analysis, $K_{H \beta-F E M}$, have been compared with those results obtained by application of the ISO Standard coefficient-based method (Method $C$ ), $K_{H \beta-C}$.

(3) A comprehensive study that includes 486 cases of design has been accomplished, including variations of the location of the gears over the shafts, the face width of the gears, and the diameter and length of the shafts.

(4) A correlation between the face load factor $K_{H \beta-F E M}$ and the angular misalignment in the plane of action has been observed, providing a relative maximum of $K_{H \beta-F E M}$ when the location of the gears over the shafts is changed. Such a maximum is not observed in the variation of $K_{H \beta-C}$ with the location of the gears over the shafts.

(5) A mapping of the maximum and minimum values of the relative difference between $K_{H \beta-C}$ and $K_{H \beta-F E M}$, considering as variables the location of the gears over the shafts and the ratio of the face width over the shaft length, has been obtained, providing valuable information for gear designers.

\section{Acknowledgments}

The authors express their deep gratitude to the Spanish Ministry of Science and Innovation for the financial support of research projects ref. DPI2010-20388-C02-01 and DPI2010-20388-C02-02. 


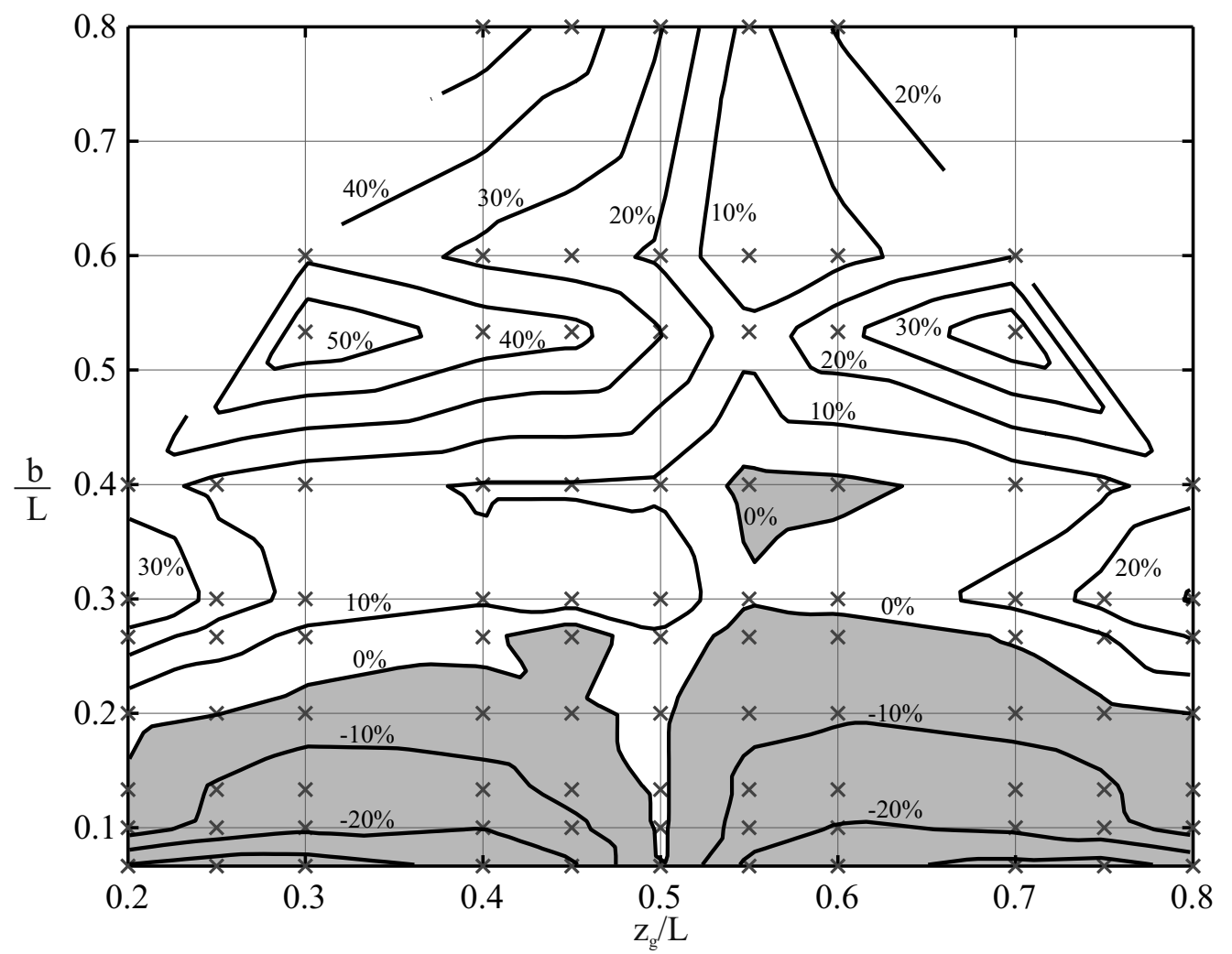

(a)

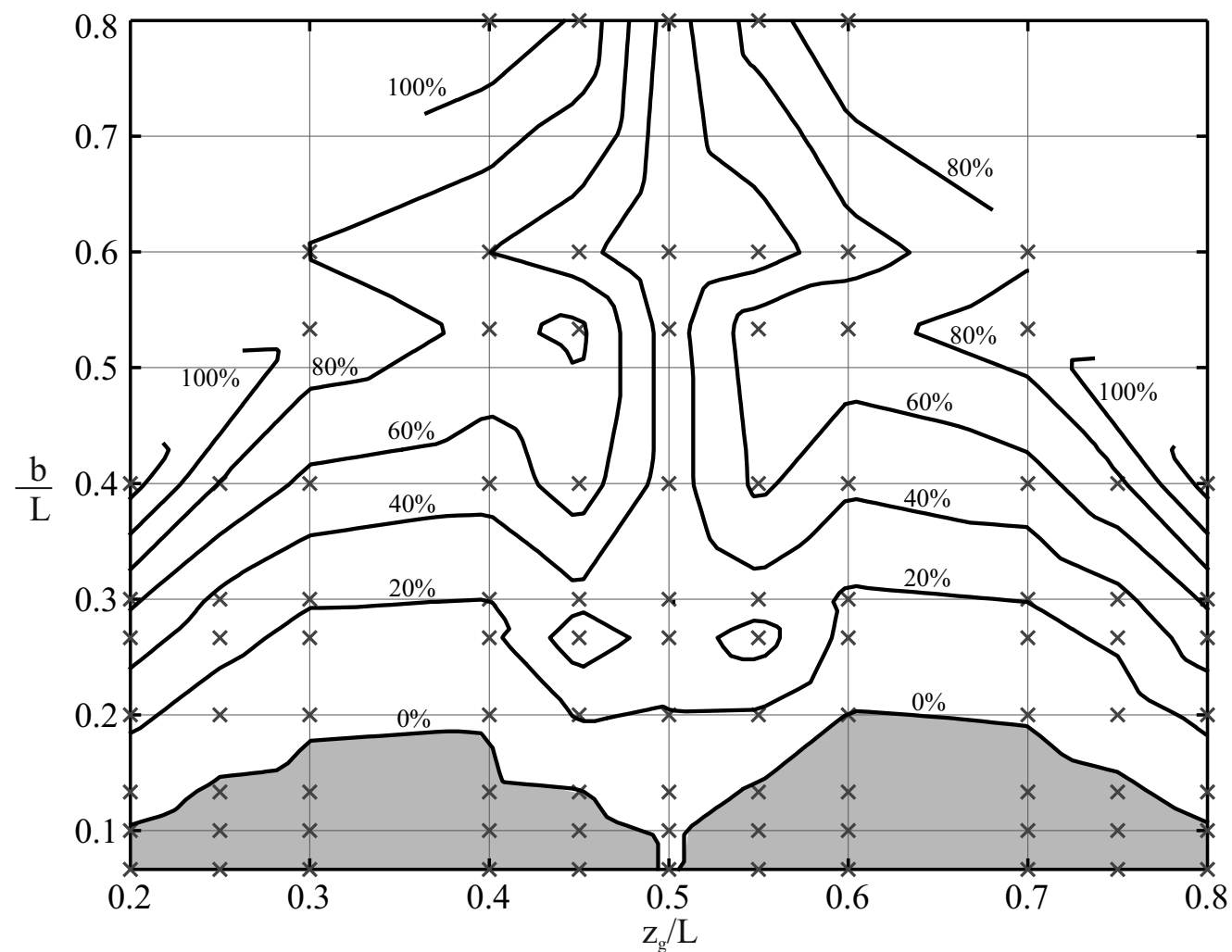

(b)

Figure 13: Mapping of (a) minimum and (b) maximum enveloping values of $\epsilon_{\text {rel }}$ for each pair of values $\left(z_{g} / L, b / L\right)$. 


\section{References}

[1] Standard ISO 6336-1, Calculation of Load Capacity of Spur and Helical Gears, part 1, International Standard Organization, Geneva, 2006.

[2] Standard ISO 6336-2, Calculation of Load Capacity of Spur and Helical Gears, part 2, International Standard Organization, Geneva, 2006.

[3] Standard ISO 6336-3, Calculation of Load Capacity of Spur and Helical Gears, part 3, International Standard Organisation, Geneva, 2006.

[4] Standard ANSI/AGMA 2001-D04, Fundamental Rating Factors and Calculation Methods for Involute Spur and Helical Gear Teeth, American Gear Manufacturers Association, Alexandria, 2004.

[5] J. I. Pedrero, Determination of the ISO tooth form factor for involute spur and helical gears, Mechanism and Machine Theory 122 (2000) 331-336.

[6] J. I. Pedrero, Approximate method for the determination of the bending strength geometry factor for external spur and helical gear teeth, Journal of Mechanical Design 34 (1999) 89-103.

[7] M. A. S. Arikan, Direct calculation of AGMA geometry factor J by making use of polynomial equations, Mechanics Research Communications 29 (2002) 257-268.

[8] D. C. Feng, An accurate method for calculating load distribution factor Kp of involute gears, Progress of Precision Engineering and Nano Technology 339 (2007) 458-462.

[9] S. Glodez, Z. Ren, Computational determination of the face load factor $K_{H \beta}$ for spur gears, Proceedings of the 5th International Design Conference, Dubrovnik, 1998.

[10] I. Atanasovska, V. Nikolic, 3D spur gear FEM model for the numerical calculation of face load factor, Mechanics, Automatic Control and Robotics 6 (2006) 131-143.

[11] I. Atanasovska, Influence of stiffness and base pitch deviation on load distribution between tooth pairs and involute gear load capacity, Machine Design (2007) 259-264.

[12] I. Atanasovska, V. Nikolic, Influence of addendum modification coefficient on the gear load capacity, Proceedings of the 16th European Conference of Fracture, Alexandroupolis, 2006.

[13] I. Atanasovska, R. Mitrovic, D. Momcilovic, Analysis of the nominal load effects on gear load capacity using the finite element method, Proceedings of the Institution of Mechanical Engineers Part C, Journal of Mechanical Engineering Science 224 (2010) 2539-2548.

[14] J. D. Smith, Estimation of the static load distribution factor for helical gears, Proceedings of the Institution of Mechanical Engineers Part C, Journal of Mechanical Engineering Science 209 (1995) 193-199.

[15] M. Stegic, M. Vrankovic, Assesstment of the non-uniform load distribution of gear pair, Proceedings of the 6th International Design Conference, Dubrovnik, 2000.

[16] V. Senthil Kumar, D. V. Muni, G. Muthuveerappan, Optimization of asymmetric spur gear drives to improve the bending load capacity, Mechanism and Machine Theory 47 (2000) 829-858.

[17] F. M. Khoshnaw, N. M. Ahmed, Effect of the load location along the involute curve of spur gears on the applied stress at the fillet radius, Materialwissenschaft Und Werkstofftechnik 39 (2008) 407-414.

[18] S. Li, Effects of machining errors, assembly errors and tooth modifications on loading capacity, load-sharing ratio and transmission error of a pair of spur gears, Mechanism and Machine Theory 42 (2007) 698-726.

[19] S. Li, Finite element analyses for contact strength and bending strength of a pair of spur gears with machining errors, assembly errors and tooth modifications, Mechanism and Machine Theory 42 (2007) 88-114.

[20] M.A. Hotait, D. Talbot, A. Kahraman, An investigation of the influence of shaft misalignments on bending stresses of helical gear with lead crown, Proceedings of the 10th International Power Transmission and Gearing Conference, Las Vegas, 2007.

[21] T. Koide, S. Oda, S. Matsuura, A. Kubo, Equivalent misalignment of gears due to deformation of shafts, bearings and gears (model proposal and development of calculation program), JSME International Journal Series C, Mechanical Systems, Machine Elements and Manufacturing 46 (2003) 1563-1571.

[22] J. Argyris, A. Fuentes, F. L. Litvin, Computerized integrated approach for design and stress analysis of spiral bevel gears, Computer Methods in Applied Mechanics and Engineering 191 (2002) 1057-1095.

[23] V. Roda-Casanova, J. L. Iserte-Vilar, F. Sanchez-Marin, A. Fuentes, I. Gonzalez-Perez, Depelopment and comparison of shaft-gear models for the computation of gear misalignments due to power transmission, Proceedings of the 11th International Power Transmission and Gearing Conference, Washington D.C., 2011.

[24] G.A. Korn, T.M. Korn, Mathematics Handbook for Scientist and Engineers, second ed., McGraw-Hill, New York, 1968.

[25] Dassault Systemes, ABAQUS/Standard User's Manual, Simulia, Pantucket, 1998. 


\section{List of Figures}

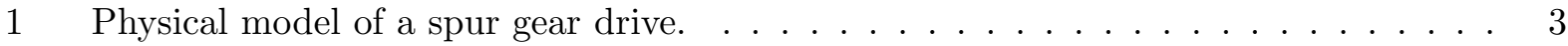

2 Finite element mesh for one gear tooth. . . . . . . . . . . . . . . . . 3

3 Finite element model of the gear drive. . . . . . . . . . . . . . . . 4

4 For the determination of the face load factor by finite element analysis. . . . . . . . 5

5 Bearing contact on the pinion tooth surface in the case of $b=40 \mathrm{~mm}$., $L=150 \mathrm{~mm}$., $d_{s h}=25 \mathrm{~mm}$. when: (a) $z_{g}=0.4 L$, (b) $z_{g}=0.5 L$, (c) $z_{g}=0.6 L$, and (d) $z_{g}=0.7 L . \quad 8$

6 Comparison for some cases of design of the face load factor $K_{H \beta-F E M}$ with: (a) and (c) the angular misalignment and, (b) and (d), the center distance error. . . . . . . 9

7 Variation of $K_{H \beta-F E M}$ and $K_{H \beta-C}$ with several values of $d_{s h}$ for some cases of design. 10

8 Variation of $K_{H \beta-F E M}$ and $K_{H \beta-C}$ with several values of $b$ for some cases of design. 11

$9 \quad$ Variation of $K_{H \beta-F E M}$ and $K_{H \beta-C}$ with several values of $L$ for some cases of design. 12

10 Variation of $K_{H \beta-F E M}$ and $K_{H \beta-C}$ with several values of $z_{g}$ for some cases of design. 13

11 Linear regressions between $\epsilon_{\text {rel }}$ and the ratio $b / L$ for four representative values of $z_{g} / L \ldots \ldots \ldots \ldots \ldots \ldots \ldots \ldots \ldots \ldots \ldots$

12 Envelope curves to the (a) minimum values and (b) maximum values of $\epsilon_{r e l}$ in the

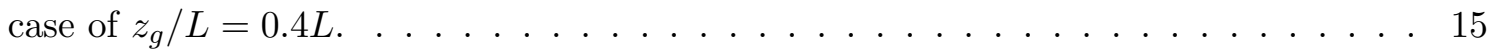

13 Mapping of (a) minimum and (b) maximum enveloping values of $\epsilon_{\text {rel }}$ for each pair

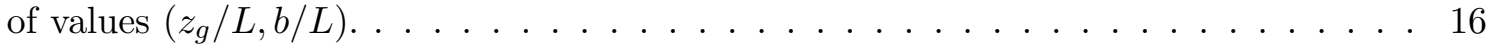

